\title{
A EROSIVIDADE DAS CHUVAS EM FORTALEZA (CE). I - DISTRIBUIÇÃO, PROBABILIDADE DE OCORRÊNCIA E PERÍODO DE RETORNO - 1a APROXIMAÇÃO(1)
}

\author{
A. S. DIAS ${ }^{(2)} \&$ J . R. C. SILVA(3)
}

\begin{abstract}
RESUMO
A aplicação da E quação Universal de Perdas de Solo para previsão de perdas por erosão e para planejamento conservacionista requer a avaliação de valores locais de índices de erosividade da chuva. Visando contribuir para o conhecimento desses índices na zona litorânea do estado do Ceará, os objetivos do presente estudo foram: (a) determinar o fator $\mathbf{R}$ e os valores anuais do índice $\mathrm{EI}_{30}$, sua distri buição mensal, probabilidade de ocorrência e períodos de retorno em Fortaleza (CE) no período de 1962 a 1981, e (b) criar um banco de dados que permita, numa análise posterior, avaliar as correlações entre o índice $\mathrm{EI}_{30}$ e as chuvas mensais, com vistas em simplificar o cálculo desse índice e atualizar seus valores durante o período de 1982 a 2000 . A energia cinética total, intensi dades uniformes, intensi dades máximas em 30 minutos e o índice $\mathrm{EI}_{30} \mathrm{em}$ chuvas individuais foram determinados em 7.300 diagramas diários de pluviógrafo do período de 1962 a 1981, disponíveis na E stação Meteorológica da Universidade Federal do Ceará, em Fortaleza. Distribuições de freqüência dos valores máximos individuais e anuais do índice $\mathrm{EI}_{30}$ e seus períodos de retorno foram calculados e plotados em curvas de probabilidades de ocorrência desses valores. No período de 20 anos, o valor do fator $R$ em Fortaleza foi de 6.774 com uma amplitude de 2.237 a $12.882 \mathrm{MJ} \mathbf{m m}$ (ha $\mathrm{h}$ ano) ${ }^{-1}$. Esse valor médio anual pode ocorrer ou ser superado pelo menos uma vez a cada 2,2 anos, com uma probabilidade de $46 \%$. Os valores individuais máximos estimados para os períodos de retorno de 2, 5, 20, 50 e 100 anos foram de 1.363, 2.415, 3.783, 5.950 e $8.000 \mathrm{MJ} \mathrm{mm}(\text { ha } h)^{-1}$, respectivamente. Nos meses de fevereiro a maio, são esperadas as mais altas perdas de solo e água, posto que $70 \%$ do valor anual do índice de erosividade ocorre nesse período, quando é utilizado o preparo convencional do solo e a cobertura vegetal é incipiente.
\end{abstract}

Termos de indexação: fator $\mathbf{R}$, planejamento conservacionista, índice $\mathrm{EI}_{30}$, E quação Universal de Perdas de Solo.

(1) Parte da Tese de Mestrado em Solos e Nutrição de Plantas do primeiro autor, apresentada à Universidade F ederal do Ceará UFC. Recebido para publicação em abril de 2002 e aprovado em novembro de 2002.

(2) Professor Adjunto da Universidade Estadual do Maranhão- UEMA. Caixa Postal 09, CEP 65000-000 São Luís (MA). Bolsista da CAPES. E-mail: asolondias@zipmail.com.br

(3) Professor Titular do Departamento de Ciência do Solo da UniversidadeF ederal do Ceará - UFC. Caixa Postal 12.168, CEP 60021970 Fortaleza (CE). Bolsista do CNPq. E-mail: joesilva@ufc.br 


\begin{abstract}
SUMMARY: RAINFALL EROSIVITY IN FORTALEZA, CEARÁ STATE, BRAZIL.I - DISTRIBUTION, PROBABILITY OF OCCURRENCE AND RETURN PERIOD - IST APPROXIMATION
\end{abstract}

\begin{abstract}
Theuseof theU niversal Soil Loss Equation to predict erosion losses and for conservation planning requires an evaluation of index values of local rainfall erosivity. As a contribution to knowledge on theseindexes in the coastal zone of Ceará State, the objectives of this study were: (a) to determinetheR factor and theannual $\mathrm{EI}_{30}$ index values, its monthly distribution, probability of occurrenceand return peri ods in Fortal eza, Ceará State, Brazil for theperiod of 1962 to 1981, and (b) to create a data bank that al lows, by a subsequent analysis, the assessment of correlation between the $\mathrm{E}_{30}$ index and monthly rainfall amounts in order to simplify the index calculation and to update its values for the years 1982 to 2000 . Total rainfall kinetic energy, uniform intensities, maximum 30 minutes intensity and the $\mathrm{EI}_{30}$ index for individual rainstorms were determined on 7,300 daily rain gauge charts from 1962 to 1981, availabl eat the Meteorol ogical Station of theFederal University of Ceará, in F ortal eza. Thedistribution frequency for themaximum individual and annual $\mathrm{EI}_{30}$ values and their return periods were cal culated and plotted on curves of occurrence probability of thesevalues. Over the 20 years period, the R factor found in Fortal eza was 6,774 in a range from 2,237 to $12,881 \mathrm{MJ} \mathrm{mm}$ (ha $\mathrm{h} \mathrm{y})^{-1}$ and this average annual value is expected to occur, or to beexceeded, at least oncein 2.2 years with an occurrenceprobability of $46 \%$. Maximum individual $\mathrm{EI}_{30}$ values estimated for return periods of 2, 5, 20, 50 and 100 years were 1,363, $2,415,3,783,5,950$ and $8,000 \mathrm{MJ} \mathrm{mm}(\mathrm{ha} \mathrm{h})^{-1}$, respectively. Distribution of thel ocal erosivity showed that $97 \%$ of the annual $\mathrm{EI}_{30}$ occurs in the first semester of the year. Highest soil and water losses are to beexpected during the months of F ebruary to May, since $70 \%$ of the annual erosivity index val ueoccurs in this quarter of theyear, when conventional tillageis used for seedbed preparation and the canopy is incipient.
\end{abstract}

Index terms: $\mathrm{R}$ factor, conservation planning, $\mathrm{EI}_{30}$ index, Universal Soil Loss Equation.

\section{INTRODUÇÃO}

A demanda de produtos agrícolas vem crescendo rapidamente em resposta tanto ao crescimento exponencial da população, quanto à melhoria de seu poder aquisitivo. Além disso, no Brasil, o maior consumo de proteína animal, forçando a maior produção degrãos para rações, e, mais recentemente, a demanda de combustível derivado da biomassa da cana-deaçúcar vêm requerendo, cada vez mais, sol os produtivos para satisfazer a essas crescentes necessidades.

Há 18 anos, Brown (1984) alertava que, em termos gl obais, o resultado desse incessável aumento de utilização agrícola das terras vinha exercendo forte pressão nos solos, muitos dos quais já não podiam atender à necessidade de produção autosustentável em virtude da aceleração das taxas de erosão. Atualmente, tal fatojá éuma realidade, pois, no Ceará, paral elamente ao aumento de utilização agrícola das terras, têm sido constatados o aumento da área degradada pela erosão ea el evação das taxas de perdas de solo e água bem acima de limites toleráveis. Em conseqüência, vem ocorrendo o declínio na produtividade do solo, muitos dos quais já em fase de desertificação, dada a ausência de planejamento conservacionista da maior parte dos recursos de solo e de água nesse Estado (Magalhães
\& Lima 1995; Silva, 2000). É inadiável, portanto, equacionar e propor soluções para esse grave problema. Nesse sentido, a modelagem do processo da erosão e seu controle éatualmente uma eficiente estratégia que vem sendo utilizada no planejamento do uso, manejo e conservação do solo.

A Equação Universal de Perdas de Solo (EUPS) é um model o empírico que estima as perdas médias anuais de solo de determinado local, permitindo orientar o planejamento conservacionista com base na seleção de combinações de uso do solo, manejo da vegetação e práticas conservacionistas capazes de manter essas perdas em níveis toleráveis (Wischmeier \& Smith, 1978). A EUPS abrange em um modelo matemático todos os fatores que influenciam a erosão pelo impacto das gotas de chuva e pela enxurrada sendo expressa como $A=$ R.K.LS.C.P, em que A representa as perdas médias anuais de solo $\left(\mathrm{Mg} \mathrm{ha}^{-1} \mathrm{ano}^{-1}\right)$, $\mathrm{R}$ é o fator erosividade da chuva dado em $\mathrm{MJ} \mathrm{mm}$ (ha $\mathrm{h}$ ano) ${ }^{-1}$ e K é o fator erodibilidade do solo dado em $\mathrm{Mg}$ ha $\mathrm{h}$ (ha MJ mm)-1. Osfatores LS, C eP sãoadimensionais, expressando relações entre as perdas de solo que ocorrem em determinados comprimento de rampa (L), declividade do terreno (S), culturas eseu manejo (C) e práticas conservacionistas (P) e as perdas que ocorrem em uma parcela-padrão. 
A caracterização do fator $\mathrm{R}$ da EUPS requer o cál culo do índice de erosividade das chuvas $\left(\mathrm{EI}_{30}\right)$, cujo valor é obtido pela multiplicação de dois parâmetros específicos das precipitações erosivas de dado local: energia cinética total da chuva $(E)$ e intensidade máxima em 30 min $\left(I_{30}\right)$. Tomando os val ores desse índice para todas as chuvas individuais erosivas que ocorrem em cada mês do ano, tem-se o $\mathrm{EI}_{30}$ mensal, cuja soma caracteriza o $\mathrm{EI}_{30}$ anual. A média anual desse índice, determinada na mais longa série histórica de dados de pluviografia disponível, representa o fator $\mathrm{R}$ do local em estudo. Mais de 30 anos de determinações em parcelas com col etores de enxurrada indicaram que quando todos os demais fatores que influem na erosão, exceto a chuva, são mantidos constantes, as perdas de solo em áreas cultivadas são diretamente proporcionais ao índice $\mathrm{EI}_{30}$ (Wischmeier, 1962).

Com o avanço das pesquisas sobre a erosão, al gumas inovações no método de determinação dos fatores da EUPS vêm sendo introduzidas, visando aperfeiçoar a estimativa das perdas de solo em um model o revisado dessa equação (Renard et al., 1991; 1994). Entretanto, Hudson (1995) afirmava que, diante da simplicidade e facilidade de operação, o modelo original da EUPS ainda continuaria a ser utilizado em alguns países como um valioso guia para o planejamento conservacionista. Dentreesses países encontra-seo Brasil, ondea partir dotrabal ho pioneiro de Lombardi Neto (1977) em Campinas (SP), pesquisadores, em grande número, optaram pela adoção do modelo original da EUPS para o cál culo do F ator $\mathrm{R}$ em municípios de outros estados, tais como: Amazonas (Oliveira J r. \& Medina, 1990), Ceará (Silva, 1990), Rio Grande do Norte (Moura \& Medeiros, 1987), Paraíba (Maia Neto \& Chaves, 1997; Chaves et al., 1997), Pernambuco (Margolis et al., 1985; Cantalice \& Margolis, 1993; Albuquerque et al., 1994), Bahia (Lopes \& Brito,1993), Minas Gerais (Marques, 1996; Marques et al., 1997), Goiás (Dedecek, 1978; Silva et al., 1996), Mato Grosso (Morais et al., 1991), Mato Grosso do Sul (Carvalho et al., 1997; Castro Filho et al., 2000), Espírito Santo (Silva et al., 2000), São Paulo (Carvalho et al., 1989; Bertoni \& Lombardi Neto, 1990; Colodro et al., 2000; Roqueet al., 2001), Paraná (Rufino et al., 1993), Santa Catarina (Bertol, 1993; 1994) e Rio Grande do Sul (Cogo et al., 1978; M orais et al., 1988). Esses resultados, em conjunto com novos trabalhos em desenvolvimento por pesquisadores nacionais, representam um valioso banco de dados para a del imitação das linhas iso-erosivas do Brasil.

O litoral do Ceará, onde se situa o município de Fortal eza, éuma região intensamente cultivada pois é privilegiada por altas normais pluviométricas, em contraste com a predomi nância decondições desemiaridez em cerca de $90 \%$ do território desse Estado. Além disso, em aproximadamente 70 \% dessa região ocorrem Argissolos de alta erodibilidade, aumentando os riscos de degradação das áreas cultivadas. A ausência de informações sobre a erosividade das chuvas nessa região constitui, portanto, um obstácul o ao planejamento de controle da er osão eao manejo racional dos solos locais, tendo em vista uma agricultura produtiva e sustentável.

Nesse contexto, os objetivos destetrabal ho foram: (a) determinar os índices $\mathrm{EI}_{30}$ mensais e anuais em Fortal eza (CE), no período de 1962 a 1981; (b) avaliar a distribuição anual e mensal do índice de erosividade local; (c) determinar as probabilidades de ocorrência e períodos de retorno dos índices anuais de erosividade e de seus valores máximos anuais para as chuvas individuais, e (d) criar um banco de dados que permita, em uma análise posterior, avaliar a correlação entre o índice $\mathrm{EI}_{30}$ anual e os parâmetros de pluviometria, objetivando simplificar o cálculo desse índice e atualizar seus valores até o ano 2000.

\section{MATERIAL E MÉTODOS}

\section{Caracterização da área e do material do estudo}

A primeira etapa do estudo, abrangendo um período de 20 anos, foi realizada utilizando-se 7.300 diagramas diários de pluviógrafo disponíveis nos anos de 1962 a 1981, na Estação M eteorológica do Centro de Ciências Agrárias da Universidade F ederal do Ceará, situada no município deF ortal eza (CE). A referida estação, fundada em 1961, é do tipo Climática Principal e localiza-se na latitude $3^{\circ} 44^{\prime} \mathrm{S}$ e na longitude $38^{\circ} 33^{\prime} \mathrm{W}$ na altitude de $20 \mathrm{~m}$. A precipitação média anual no período estudado foi de $1.677 \mathrm{~mm}$ e a temperatura média anual de $27^{\circ} \mathrm{C}$. O clima é do tipo Aw'í, segundo a classificação de Köppen, caracterizando-se como tropical chuvoso com precipitações de verão e temperatura do mês mais frio superior a $18^{\circ} \mathrm{C}$.

O banco de dados criado no presente trabalho, no qual, em uma segunda etapa, foi analisada a correlação do índice $\mathrm{EI}_{30}$ com o coeficiente de chuva (Dias, 2002), permitiu prosseguir o estudo no período de 1982 a 2000, tendo em vista que não houve continuidade na leitura dos diagramas de pluviógrafos durante os anos posteriores a 1981.

\section{Determinação do índice de erosividade $\mathrm{EI}_{30}$ com dados de pluviografia}

Nos pluviogramas em que foram registradas as chuvas, em décimos de $\mathrm{mm}$ no eixo vertical, eo tempo no eixo horizontal, com subdivisões em intervalos de $10 \mathrm{~min}$, cobrindo um período de $24 \mathrm{~h}$, foram separados os segmentos de chuva de intensidade uniforme. Essas intensidades expressas em $\mathrm{mm} \mathrm{h}^{-}$ 1 foram identificadas a cada ponto onde ocorria uma mudança na declividade da curva do registro da chuva. Todas as chuvas de $10 \mathrm{~mm}$ ou mais, ou, ainda, as menores que $10 \mathrm{~mm}$, porém apresentando em 
$15 \mathrm{~min}, 6 \mathrm{~mm}$ ou mais, foram selecionadas como chuvas individuais erosivas. Chuvas separadas por menos de 6 horas foram computadas como uma única chuva individual para o cálculo da energia cinética e do índice de erosividade (Lombardi Neto, 1977). Digitalizados todos os valores da quantidade de chuva (mm), suas durações (mi nutos) eintensidades $\left(\mathrm{mm} \mathrm{h}^{-1}\right)$ nos pluviogramas diários do período de 1962 a 1981, esses valores foram utilizados no programa EROSIVIDADE I, desenvolvido por Freitas \& Madeira Netto $(1980)^{(4)}$. Neste, foram computadas as intensidades, as intensidades máximas em $30 \mathrm{~min}$, as energias cinéticas parciais e totais, bem como os índices de erosividade $\mathrm{EI}_{30}$ diários, mensais eanuais. Os resultados obtidos foram transformados para o Sistema I nternacional de Unidades (Foster et al.,1981) no qual a energia cinética é obtida pela equação:

$$
E=0,119+0,0873 \log I
$$

em que $\mathrm{E}$ é a energia cinética $\left(\mathrm{MJ}(\text { ha } \mathrm{mm})^{-1}\right)$ el, a intensidade $\left(\mathrm{mm} \mathrm{h}^{-1}\right)$. Para I $>76 \mathrm{~mm} \mathrm{~h}^{-1}$ utilizouse o valor de $0,283 \mathrm{MJ}$ (ha $\mathrm{mm})^{-1}$ para $E$ (F oster et al.,1981).

Seguindo o método de Wischmeier \& Smith (1978), o índice de erosividade $\mathrm{EI}_{30}\left(\mathrm{MJ}\right.$ (ha $\mathrm{mm} \mathrm{h}^{-1}$ ) de cada chuva individual erosiva foi calculado pela multiplicação da energia cinética pela sua intensidade máxima em $30 \mathrm{~min}\left(\mathrm{~mm} \mathrm{~h}^{-1}\right)$. O $\mathrm{EI}_{30}$ mensal foi calculado pela adição dos valores desse índice para todas as chuvas individuais erosivas que ocorreram em cada mês do ano, cuja soma, por sua vez, caracterizou oEI $\mathrm{E}_{30}$ anual. A média anual desse índice, determinada nos anos de 1962 a 1981, representou ofator $\mathrm{R}$ de F ortaleza nesse período de 20 anos.

\section{Probabilidade de ocorrência e período de retorno do índice $\mathrm{EI}_{30}$}

Nas análises de probabilidade de ocorrência e do período de retorno do índice $\mathrm{EI}_{30}$ determinados para os anos de 1962 a 1981, foram utilizadas a lei de probabilidade logarítmica e a teoria de valores extremos (Schwab et al., 1966). Utilizou-se o programa Probability P lot - Logl ogi stic distribution (MINITAB, 1998) como auxílio na confecção do gráfico da plotagem dos valores determinados das probabilidades de ocorrência, dos períodos deretorno e da curva de distribuição de probabibilidade.

\section{Distribuição anual e mensal da percentagem acumulada da erosividade}

Os val ores dos índices $\mathrm{EI}_{30}$ médios mensais foram divididos pelo seu valor médio anual, encontrando-

\footnotetext{
(4) FREITAS, P.L. \& MADEIRA NETTO, J.S. Um programa computacional para cálculo dos índices de erosividade das chuvas. Brasília, EMBRAPA-SNLCS.1980. Não paginado.
}

se os respectivos valores relativos mensais. Esses valores, transformados em percentagens, foram plotados numa curva de distribuição mensal em um gráfico no qual a ordenada representa a percentagem acumulada do $\mathrm{EI}_{30}$ para cada mês, e a abscissa, os meses do ano.

\section{RESULTADOS E DISCUSSÃO}

\section{Distribuição anual e mensal do índice de erosividade $\mathrm{EI}_{\mathbf{3 0}}$}

No período de 20 anos de determinações da erosividade, encontrou-se, para Fortaleza (CE), um valor médio anual do índice $\mathrm{EI}_{30}$ igual a $6.774 \mathrm{MJ} \mathrm{mm}$ (ha h ano-1, com um desvio-padrão de 3.083 e coeficiente de variação de $46 \%$ (Quadro 1).

Esse val or do $\mathrm{EI}_{30}$ é semel hante aos encontrados por vários autores brasileiros em clima tropical, conforme as seguintes referências em que os val ores médios anuais da erosividade, ou sua amplitude, encontrados em MJ mm (ha $h$ ano) ${ }^{-1}$, são citados entre parênteses: Cogo (1978), em Guaíba (RS), (6.275); Carvalho et al. (1997), em Selvíria (MS), (6.728); Pissarra et al. (2000), em Pereira Barreto (SP), (6.966); Bertoni \& Lombardi Neto (1990), no litoral doestado deSãoPaulo, (6.000 a 7.500); Rufino et al. (1993), no estado do Paraná, (5.500 a 12.000); Castro Filho et al. (2000), na Bacia do Rio Paraná (5.000 a 14.000), e Maia Neto \& Chaves (1997), no estado da Paraíba (2.000 a 8.000). Em outras localidades, esse índice apresentou val ores médios anuais superiores aos do local em estudo, conforme mostrado nas referências seguintes: Cogo (1978), em Ijuí (RS), (8.606) e Passo Fundo (RS), (7.342); Dedecek (1978), em Brasília (DF), (8.319); Carvalho et al. (1989), em Mococa (SP), (7.747); Oliveira J r. \& Medina (1990), em Manaus (AM), (14.129); Morais et al. (1991), no Sudoeste do estado de Mato Grosso, (7.830 a 8.439); Silva et al. (1996), em Goiânia (GO), (8.355); Colodro et al. (2000), em Teodoro Sampaio (SP) (7.172), e Roque et al. (2001), em Piraju (SP), (7.074). Entretanto, quando comparada com localidades sob clima semi-árido, a erosividade média anual de Fortaleza apresentou-se superior, como pode ser apreciado nas referências seguintes: Margolis et al. (1985), em Caruaru (PE) (2.060); Lopes \& Brito (1993), na região do Médio São Francisco no pólo Petrolina (PE) - J uazeiro (Ba) (3.772); Chaves et al. (1997), em Patos (PB) (5.200); Albuquerque et al. (2001), em Sumé (PB) (4.298).

Valores do índice médio anual em outros locais do Brasil também podem ser encontrados na literatura pertinenteao tema em estudo. Entretanto, esses val ores não se prestam a comparações com o presente estudo, posto que foram determinados em períodos demasiadamente curtos ( 1 a 4 anos), incluindo, em certos casos, anos com volumes de 
Quadro 1. Distribuição mensal e anual do índice de erosividade $\mathrm{EI}_{30}$ de Fortaleza (CE) no período de 1962 a 1981

\begin{tabular}{|c|c|c|c|c|c|c|c|c|c|c|c|c|c|}
\hline \multirow{3}{*}{ Ano } & \multicolumn{13}{|c|}{ Índice de erosividade E I 30} \\
\hline & \multicolumn{12}{|c|}{ Mensal } & \multirow{2}{*}{ Anual } \\
\hline & jan. & fev. & mar. & abr. & maio & jun. & jul. & ago. & set. & out. & nov. & dez. & \\
\hline & \multicolumn{12}{|c|}{ - MJ mm (ha h)-1 } & MJ mm (ha $h$ ano) $)^{-1}$ \\
\hline 1962 & 1.069 & 265 & 343 & 383 & 177 & 0 & 0 & 0 & 0 & 0 & 0 & 0 & 2.237 \\
\hline 1963 & 2.080 & 1.315 & 3.855 & 4.493 & 422 & 39 & 0 & 0 & 0 & 0 & 137 & 540 & 12.881 \\
\hline 1964 & 1.619 & 2.325 & 2.413 & 3.375 & 1.521 & 275 & 49 & 0 & 29 & 0 & 0 & 20 & 11.625 \\
\hline 1965 & 608 & 49 & 2.158 & 2.659 & 736 & 814 & 108 & 0 & 0 & 0 & 0 & 0 & 7.132 \\
\hline 1966 & 69 & 29 & 177 & 3.453 & 1.629 & 608 & 324 & 0 & 69 & 0 & 0 & 0 & 6.357 \\
\hline 1967 & 59 & 3.149 & 1.167 & 1.089 & 4.640 & 442 & 275 & 20 & 0 & 0 & 0 & 0 & 10.840 \\
\hline 1968 & 1.295 & 177 & 785 & 1.629 & 1.570 & 29 & 128 & 0 & 0 & 177 & 0 & 98 & 5.886 \\
\hline 1969 & 108 & 461 & 3.296 & 1.423 & 5.219 & 294 & 549 & 0 & 0 & 0 & 0 & 0 & 11.350 \\
\hline 1970 & 314 & 20 & 1.089 & 608 & 147 & 245 & 20 & 0 & 0 & 0 & 186 & 0 & 2.629 \\
\hline 1971 & 1.570 & 569 & 1.844 & 589 & 1.334 & 628 & 2.443 & 39 & 0 & 0 & 0 & 137 & 9.153 \\
\hline 1972 & 0 & 304 & 893 & 775 & 1.736 & 530 & 226 & 69 & 0 & 0 & 0 & 69 & 4.601 \\
\hline 1973 & 540 & 1.285 & 1.050 & 1.148 & 2.462 & 422 & 353 & 49 & 118 & 0 & 49 & 0 & 7.475 \\
\hline 1974 & 1.167 & 608 & 2.404 & 834 & 618 & 451 & 0 & 206 & 255 & 0 & 0 & 432 & 6.975 \\
\hline 1975 & 167 & 1.373 & 2.688 & 549 & 2.109 & 471 & 196 & 0 & 29 & 0 & 69 & 29 & 7.681 \\
\hline 1976 & 216 & 1.128 & 873 & 1.364 & 245 & 206 & 59 & 59 & 0 & 0 & 20 & 0 & 4.169 \\
\hline 1977 & 648 & 255 & 687 & 2.963 & 775 & 775 & 285 & 69 & 0 & 0 & 0 & 0 & 6.455 \\
\hline 1978 & 157 & 294 & 540 & 177 & 697 & 167 & 618 & 0 & 39 & 0 & 0 & 157 & 2.845 \\
\hline 1979 & 118 & 1.069 & 1.452 & 383 & 854 & 79 & 0 & 157 & 343 & 0 & 0 & 0 & 4.454 \\
\hline 1980 & 1.638 & 2.668 & 324 & 108 & 137 & 226 & 39 & 118 & 29 & 0 & 0 & 0 & 5.288 \\
\hline 1981 & 422 & 677 & 2.688 & 893 & 451 & 108 & 0 & 0 & 0 & 0 & 0 & 206 & 5.445 \\
\hline Média & 693 & 901 & 1.536 & 1.445 & 1.374 & 340 & 284 & 39 & 46 & 9 & 24 & 84 & 6.774 \\
\hline Desvio-padrão & 655 & 906 & 1.066 & 1.259 & 1.395 & 246 & 541 & 60 & 93 & 39 & 52 & 152 & 3.083 \\
\hline C.V. (\%) & 95 & 101 & 69 & 87 & 102 & 72 & 191 & 152 & 202 & 449 & 219 & 180 & 46 \\
\hline
\end{tabular}

chuvas muito superiores ou inferiores às normais pluviométricas locais. Geralmente, a ausência de registros pluviográficos anteriores e a necessidade de agilizar as informações sobre a erosi vidade, ainda que em nível preliminar ou exploratório, motivaram essas determi nações de curto prazo. Nessa situação, encontram-se as referências de Silva et al. (1981), em Quixadá (CE ), (7.087); M oura \& M edeiros (1987), em Mossoró (RN), (16.767); Silva (1990), em U bajara (CE ), (5.961) e em Tianguá (3.030); Marques (1996), em Sete Lagoas (MG) (5.835), e Silva et al. (2000), em Aracruz (ES) (4.126).

Albuquerque et al. (1998), em Sumé (PB), e Carvalho \& Hernani (2001), em Dourados (MS), com base em dados de chuvas individuais erosivas ocorridas em períodos de 5 anos, introduziram parâmetros da enxurrada em model os matemáticos para aprimorar a estimativa da erosividade. Essa é uma alternativa que merece atenção dos pesquisadores sobre o tema em apreço. Entretanto, um período mais di latado detempo de determinações em diferentes solos e condições de climas locais deveria ser considerado para a avaliação dessa inovação metodológica na estimativa da erosividade.

A grande variação dos valores anuais da erosividade(2.237 a $12.881 \mathrm{MJ} \mathrm{mm}$ (ha $\mathrm{h}$ ano)-1), em
Fortaleza (Quadro 1), é coerente com observações deWischmeier (1976) que detectou, em determinados anos, valores iguais a menos da metade ou até mais do dobro do $\mathrm{EI}_{30}$ médio anual determinado em longos períodos (22 anos). Essa variação, segundo esse autor, está relacionada com a grande variabilidade temporal das chuvas, bem como com efeitos cíclicos que ocorrem em longos prazos.

\section{Distri bui ção das chuvas e das chuvas erosivas}

Os totais de 162 chuvas e de $1.677 \mathrm{~mm}$ foram os valores médios anuais encontrados para o número de chuvas e de suas alturas pluviométricas, enquanto os valores desses parâmetros para as chuvas erosivas foram iguais a 41 e $959 \mathrm{~mm}$, respectivamente. Esses valores médios anuais das chuvas erosivas correspondem a 25,3 e 57,2 \% dos que foram encontrados para as médias anuais do número de chuvas e de suas alturas pluviométricas determinadas no período de 1962 a 1981. Entretanto, a concentração dessas chuvas no período de janeiro a junho ( $F$ igura 1 ) constitui uma característica bem mais importante que esses percentuais médios anuais. No primeiro semestre do ano, ocorreu um total de $866 \mathrm{~mm}$ de chuvas erosivas, correspondendo a $90,3 \%$ da média das chuvas erosivas anuais. 


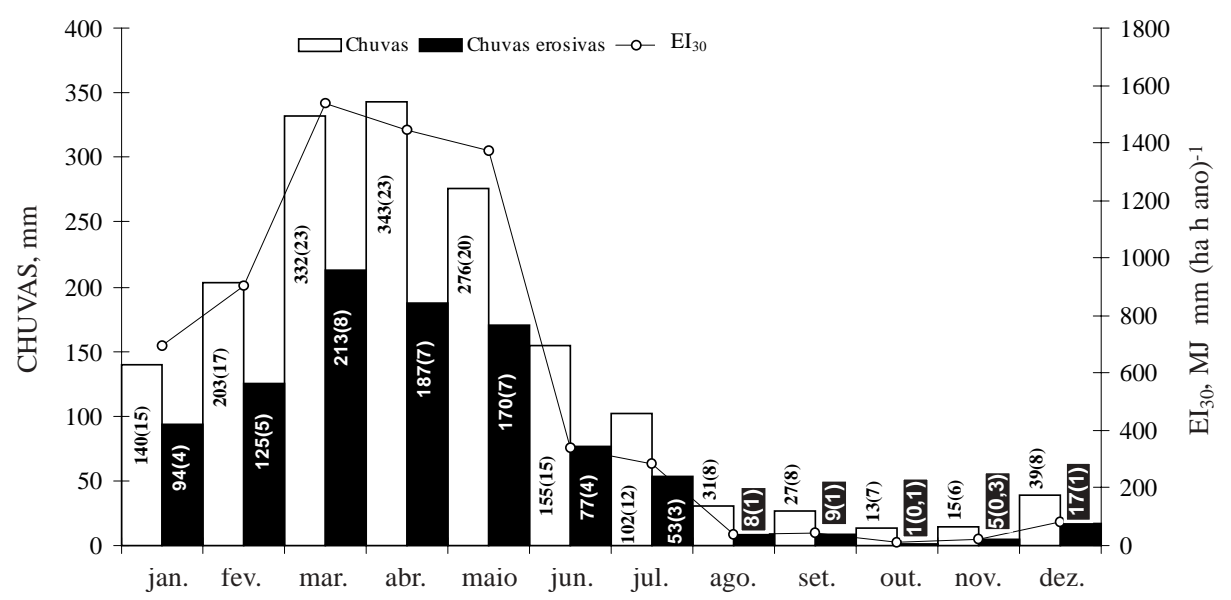

Figura 1. Distribuição de valores médi os mensais das chuvas e das chuvas erosi vas em relação aos valores médios mensais do índice $\mathrm{EI}_{30}$ no período de 1962 a 1981, em Fortaleza (CE). Valores entre parêntese indicam o número médio de chuvas abaixo dos quais são indicados os valores médios mensais das chuvas em mm.

Os riscos de erosão aumentam particularmente nos meses de fevereiro a maio, visto que, somente nesses quatro meses, as chuvas erosivas (695 mm) correspondem a $72,5 \%$ do total médio anual, sendo responsáveis por um valor do índice de erosividade $\mathrm{El}_{30}$ igual a $4.709 \mathrm{~mm}$ (ha $\mathrm{h}$ ano)-1, ou seja, $70 \%$ do total médio anual. Esses al tos percentuais de chuvas erosivas em relação ao total de chuvas que ocorrem durante o ano coincidem com as observações de Hudson (1995) relacionadas com o maior potencial erosivo das chuvas tropicais em relação às chuvas de clima temperado. Esse autor estimou que, em clima temperado, com menores normais pluviométricas, apenas cerca de $5 \%$ das chuvas são erosivas enquanto em clima tropical, como o do presente estudo, as normais pluviométricas, as intensidades e energias cinéticas são mais al tas, com as chuvas erosivas atingindo em torno de $40 \%$ do total anual das chuvas, explicando, dessa forma, as razões pelas quais a erosão é um problema mais grave em países com chuvas tropicais ou subtropicais.

A figura 1 mostra, ainda, que os valores da erosividade seguem, de modo geral, os das chuvas e das chuvas erosivas, destacando-se os meses de março e abril como os mais chuvosos e o mês de março como o que apresentou os maiores valores médios mensais de número de chuvas erosivas (8) e de seus volumes ( $213 \mathrm{~mm})$. Observa-se, também, que a distribuição das chuvas e da erosividade enquadra-se no padrão uni-modal, no qual as chuvas concentram-se de janeiro a junho, seguindo-se um período de estio de julho a dezembro. Segundo Hudson (1995), esse padrão de distribuição das chuvas é característico de clima tropical no qual a erosão éo resultado tanto das chuvas mais intensas do período úmi do quanto da dessecação da cobertura vegetal na estação seca do ano.
A distribuição mensal da erosividade calculada como percentagens do valor médio anual e acumulada a cada mês sob forma de uma curva mostrada na figura 2 indica a época do ano na qual ocorre o maior potencial das chuvas para provocar erosão.

Essas percentagens também são imprescindíveis ao cálculo do fator C da EUPS, uma vez que a proteção do solo por determinada cultura depende do estádio de desenvolvimento vegetativo no qual ela seencontra em relação aos valores da erosi vidade que ocorrem no aludido estádio (Wischmeier \& Smith, 1978).

Assim é que, no período de janeiro a março, correspondendo à época de preparo do solo e plantio, e no mês de abril, correspondendo à época de estabelecimento das culturas, ocorre um alto potencial de perdas de solo e água pela erosão, em face da ocorrência de $67,5 \%$ da erosividade anual apenas nesses quatro meses (Figuras 1 e 2). Essas grandes perdas por erosão, esperadas nessas épocas, são conseqüências do fato de o sol o encontrar-se sem cobertura e desagregado, particularmente, quando executado o preparo convencional (janeiro a março) com sucessivas arações e gradagens, e em abril as plantas, em seu estádio inicial de crescimento, ainda não apresentam cobertura do solo suficiente para dissipar a elevada energia cinética das gotas de chuva em queda livre. Nesse contexto, cumpre ressaltar a necessária e urgente substituição do preparo convencional do solo, ainda vigente no Ceará, pel o plantio direto no qual a pal ha age como eficiente cobertura e proteção do solo, diminuindo significativamente as perdas por erosão (De Maria, 1999; Silva, 2000).

A concentração do potencial erosivo das chuvas em poucos meses do ano também tem si do observada 
em todas as pesquisas desenvolvidas em outras regiões brasileiras. Dentre essas podem ser citadas as deBertoni \& Lombardi Neto (1990), Morais et al. (1991) e Lopes \& Brito (1993), nas quais cerca de60, 76 a 91 e $65 \%$ de toda a erosividade anual ocorrem, respectivamente, nos meses de novembro a março, janeiro a março e fevereiro a abril.

\section{Distribuição de freqüência dos valores anuais da erosividade}

Os valores doíndice $\mathrm{EI}_{30}$ anual, os valores máximos para chuvas individuais, dispostos em ordem decrescente, respectivos meses de ocorrência, períodos de retorno e probabilidades deocorrência são mostrados no quadro 2. O valor máximo da erosividade anual

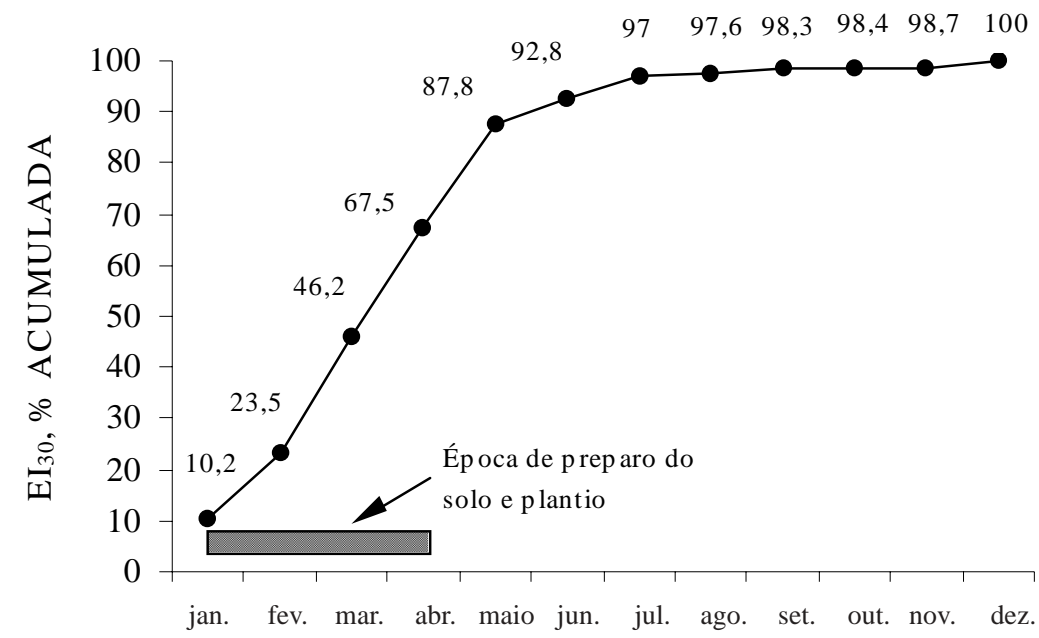

Figura 2. Distribuição percentual acumulada da erosi vidade em Fortaleza (CE).

Quadro 2. Probabi lidade de ocorrência e períodos de retorno dos valores dos índices anuais de erosi vidade $\mathrm{EI}_{30}$ de Fortaleza (CE) durante o período de 1962 a 1981

\begin{tabular}{|c|c|c|c|c|c|c|c|}
\hline \multicolumn{5}{|c|}{ Índice de erosividade (E I30) } & \multirow{3}{*}{$\begin{array}{c}\text { Número } \\
\text { de ordem }\end{array}$} & \multirow{3}{*}{$\begin{array}{l}\text { Período } \\
\text { de retorno }\end{array}$} & \multirow{3}{*}{$\begin{array}{l}\text { Probabilidade } \\
\text { de ocorrência }\end{array}$} \\
\hline \multirow[t]{2}{*}{ Ano } & \multirow{2}{*}{ Anual } & \multicolumn{3}{|c|}{$\begin{array}{c}\text { Valor máximo para chuvas } \\
\text { individuais }\end{array}$} & & & \\
\hline & & Ano & Mês & & & & \\
\hline & MJ mm (ha h ano)-1 & & & MJ $m m(h a h)^{-1}$ & $\mathrm{~m}$ & $\mathrm{~T}^{(1)}$ & $\mathrm{P}(2)$ \\
\hline 1963 & 12.881 & 1967 & Maio & 3.904 & 1 & 21,00 & 4,8 \\
\hline 1964 & 11.625 & 1969 & Maio & 3.274 & 2 & 10,50 & 9,5 \\
\hline 1969 & 11.350 & 1966 & Abril & 2.543 & 3 & 7,00 & 14,3 \\
\hline 1967 & 10.840 & 1963 & Abril & 2.540 & 4 & 5,25 & 19,1 \\
\hline 1971 & 9.153 & 1977 & Abril & 1.912 & 5 & 4,20 & 23,8 \\
\hline 1975 & 7.681 & 1971 & J ulho & 1.815 & 6 & 3,50 & 28,6 \\
\hline 1973 & 7.475 & 1973 & Maio & 1.741 & 7 & 3,00 & 33,3 \\
\hline 1965 & 7.132 & 1965 & Março & 1.696 & 8 & 2,63 & 38,0 \\
\hline 1974 & 6.975 & 1981 & Março & 1.594 & 9 & 2,33 & 42,9 \\
\hline 1977 & 6.455 & 1964 & Abril & 1.424 & 10 & 2,10 & 47,6 \\
\hline 1966 & 6.357 & 1980 & J aneiro & 1.302 & 11 & 1,91 & 52,4 \\
\hline 1968 & 5.886 & 1962 & J aneiro & 989 & 12 & 1,75 & 57,1 \\
\hline 1981 & 5.445 & 1968 & aneiro & 931 & 13 & 1,62 & 61,7 \\
\hline 1980 & 5.288 & 1975 & Fevereiro & 885 & 14 & 1,50 & 66,7 \\
\hline 1972 & 4.601 & 1970 & Marco & 749 & 15 & 1,40 & 71,4 \\
\hline 1979 & 4.454 & 1974 & Abril & 574 & 16 & 1,31 & 76,3 \\
\hline 1976 & 4.169 & 1976 & Abril & 573 & 17 & 1,24 & 80,7 \\
\hline 1978 & 2.845 & 1972 & Maio & 532 & 18 & 1,17 & 85,5 \\
\hline 1970 & 2.629 & 1979 & Março & 451 & 19 & 1,11 & 90,1 \\
\hline 1962 & 2.237 & 1978 & Março & 324 & 20 & 1,05 & 95,2 \\
\hline Média & 6.774 & - & - & 1.488 & - & - & - \\
\hline Desvio-padrão & 3.083 & - & - & 978 & - & - & - \\
\hline C.V. (\%) & 45,5 & - & - & 65,7 & - & - & - \\
\hline
\end{tabular}

(1) $\mathrm{T}=(\mathrm{N}+1) \mathrm{m}^{-1}$ em que $\mathrm{N}=20$ anos. ${ }^{(2)} \mathrm{P}=100(\mathrm{~T})^{-1}$. 
(12.881 MJ mm (ha $\mathrm{h}$ ano)-1), determinado no ano de 1963, e o mínimo (2.237 MJ mm (ha h ano)-1), determinado no ano de 1962, apresentaram, respectivamente, períodos de retorno de 21 e 1,05 anos e probabilidades de ocorrência de 4,8\%, para o primeiro, e de 95,2 \%, para o último.

Espera-se, portanto, com essas probabilidades, que esses valores máximos e mínimos possam ser igualados ou superados, pel o menos uma vez, a cada 21 anos e a cada 1,05 anos, respectivamente. Para um período deanálise de 22 anos, em Campinas (SP), Lombardi Neto (1977) encontrou valor máximo (13.832 MJ mm (ha h ano)-1) emínimo(3.443 MJ mm (ha $\mathrm{h}$ ano) ${ }^{-1}$ ) da erosividade anual, com períodos de retorno de 23 e 1,05 anos e probabilidades de ocorrência de 4,3 e 95,7 \%, respectivamente. Para um período de estudo de 23 anos, Roqueet al . (2001), em Piraju (SP), encontraram 12.940 e 3.624 MJ mm (ha $\mathrm{h}$ ano)-1 ${ }^{-1}$ para os valores máximos e mínimos de erosividade anual, com período de retorno e probabilidades de ocorrência iguais a 24 anos e 4,2 \% para o máximo e 1,04 anos e 96,2 \% para o mínimo. Certamente, os períodos de estudo diferentes do da presente análise, bem como as diferenças climáticas existentes entre Ceará e São Paulo, condicionaram valores superiores da erosividade encontrada por esses autores em relação aos de F ortal eza.

Com relação aos valores da erosividade para chuvas individuais, o valor máximo (3.904 MJ mm (ha $\mathrm{h}$ ano)-1) foi determinado no mês de maio de 1967, esperando-se que possa ser igualado ou superado, pelo menos uma vez a cada 21 anos, com probabilidade de 4,8\%, enquanto o valor mínimo (324 MJ mm (ha $\mathrm{h}$ ano)-1) ocorreu no mês de março de 1978, podendo ser superado ou igualado, pelo menos uma vez a cada 1,05 anos, com probabilidade de 95,2 \% (Quadro 2).

A curva de distribuição dos valores da erosividade anual de Fortaleza (Figura 3) seguiu o padrão lognormal, típico de eventos hidrológicos (Lombardi Neto, 1977; Carvalho et al., 1989; Roque et al., 2001).

A leitura dessa curva permite estimar os períodos de retorno e probabilidades de ocorrência para diferentes val ores da erosividade. Dessa forma, pode ser estimado que o val or médio anual do índice $\mathrm{EI}_{30}$ (6.774 MJ mm (ha $\mathrm{h}$ ano-1), correspondendo ao fator R para Fortaleza (CE), pode ocorrer com probabilidade de $46 \%$ e período de retorno de 2,2 anos, aproximadamente.

Os val ores da erosividade para chuvas individuais (Figura 4) estimados para os períodos de retorno de 2, 5, 20 e 50 anos são de 1.363, 2.415, 3.873 e $5.950 \mathrm{MJ} \mathrm{mm}$ (ha h)-1. Para o período de retorno de 100 anos, é esperado, para chuvas individuais, um valor máximo do índice de erosividade de $8.000 \mathrm{MJ} \mathrm{mm}$ (ha h) ${ }^{-1}$.

Embora no sul do País já seja possível a consulta de dados sobre a distribuição, probabilidades de

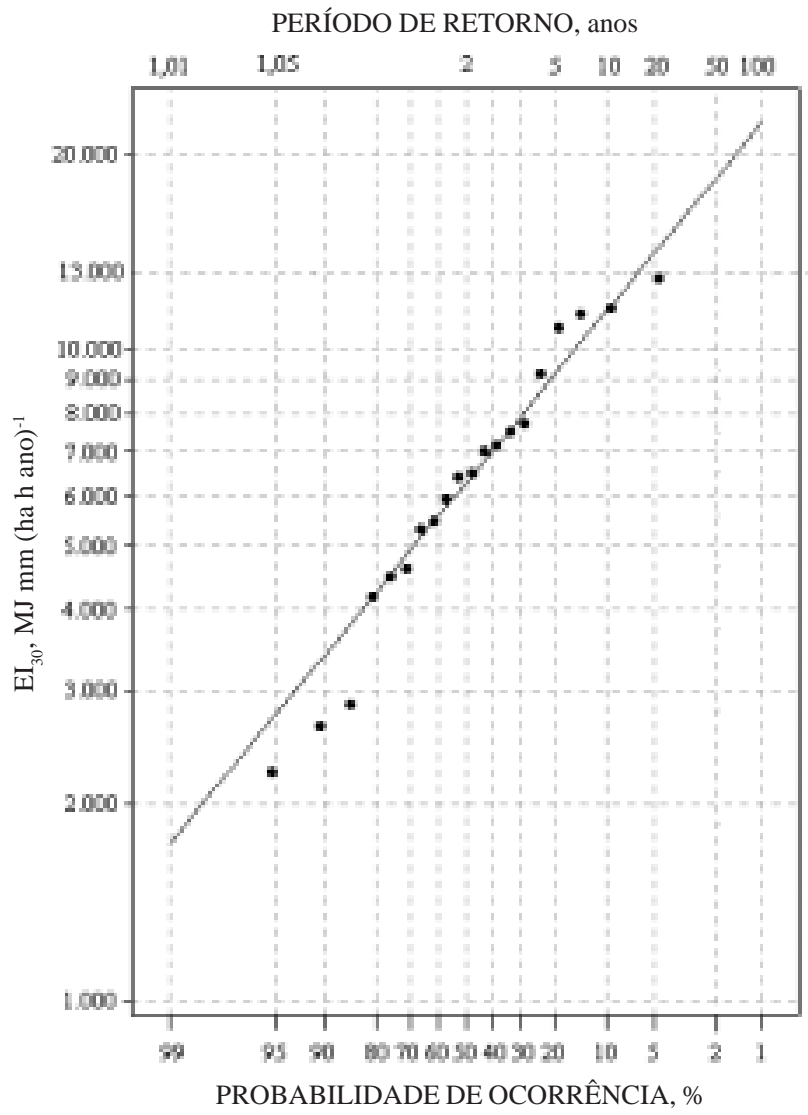

Figura 3. Curva de distribuição da probabilidade de ocorrência e período de retorno da erosi vidade anual de Fortaleza (CE ) no período de 1962 a 1981.

ocorrência e períodos de retorno de índices $\mathrm{EI}_{30}$ anuais (Lombardi N eto, 1977; Carval ho et al., 1989; Carvalho et al., 1997; Colodro et al., 2000; Roque et al., 2001), são poucos os trabal hos queinvestigaram esses parâmetros relacionados com os valores máximos do índice $\mathrm{El}_{30}$ para as chuvas individuais (Lombardi Neto, 1977; Roque et al., 2001).

Em outras regiões brasileiras, considerando séries contínuas superiores a 20 anos, esses dados referentes a valores máximos da erosividade para chuvas individuais não existem, exceto no Nordeste, onde, em um único trabal ho disponível na literatura, Chaves et al. (1997) relataram valores deerosividade e períodos de retorno para as 10 maiores chuvas ocorridas em Patos (PB) numa série de 50 anos. Esses autores encontraram valores do índice $\mathrm{EI}_{30}$ iguais a 4.251, 3.337, 1.961 e $1.556 \mathrm{MJ} \mathrm{mm}(\text { ha h) })^{-1}$ com probabilidades de ocorrência de 2, 5, 20 e $30 \%$, respectivamente. Dessa forma, os dados obtidos no presente estudo (Quadro 2 eFiguras 3 e 4) também contribuíram para aumentar as informações referentes à distribuição de freqüência de eventos extremos relativos ao índice $\mathrm{EI}_{30}$, as quais são praticamente desconhecidas no $\mathrm{N}$ ordeste brasilei ro. 


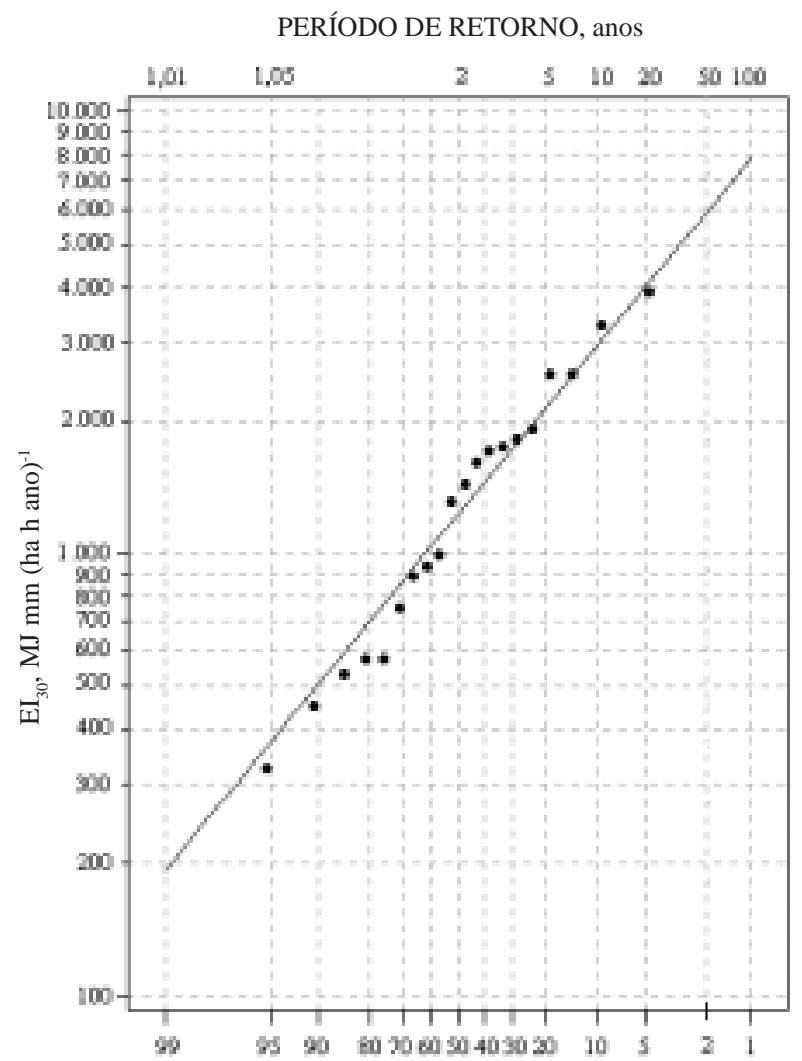

PROBABILIDADE DE OCORRÊNCIA, \%

Figura 4. Curva de probabilidade de ocorrência e período de retorno dos valores máximos do índice de erosividade $\mathrm{EI}_{30}$ para chuvas individuais em Fortaleza (CE) no período de 1962 a 1981.

\section{CONCLUSÕES}

1. O fator R da Equação Universal de Perdas de Solo, em Fortaleza (CE), foi dimensionado no valor de $6.774 \mathrm{MJ} \mathrm{mm} \mathrm{(ha} \mathrm{h} \mathrm{ano)-1,} \mathrm{com} \mathrm{um} \mathrm{erro-padrão}$ da média igual a 690, caracterizando-se as chuvas desse local como de alta erosividade.

2. A distribuição anual das chuvas enquadrouse no padrão uni-modal, no qual as chuvas concentraram-se no primeiro semestre do ano. Nos meses de janeiro a junho, verificou-se $97 \%$ do valor da erosividade média anual.

3. Os riscos de erosão aumentaram particularmente nos meses de fevereiro a maio, visto que, somente nesses quatro meses, as chuvas erosivas (695 mm) foram responsáveis por um el evado valor do índice de erosividade $\mathrm{EI}_{30}$, com um total de 4.709 MJ mm (ha h)-1 ${ }^{-1}$ ou seja, $70 \%$ do total médio anual.

4. Estimou-se, com uma probabilidade de $46 \%$, ser possível a ocorrência de um valor do índice $\mathrm{EI}_{30}$ anual, igual ou superior ao fator $\mathrm{R}$ determinado, pelo menos uma vez a cada 2,2 anos. Os valores da erosividade para chuvas individuais estimados para os períodos de retorno de 2, 5, 20 e 50 anos foram de $1.363,2.415,3.873$ e $5.950 \mathrm{MJ} \mathrm{mm}(\mathrm{ha} \mathrm{h})^{-1}$. Para o período de retorno de 100 anos é esperado, para chuvas individuais, um valor máximo do índice de erosividade de $8.000 \mathrm{MJ} \mathrm{mm} \mathrm{(ha} \mathrm{h)-1,} \mathrm{com} 1 \%$ de probabilidade de ocorrência.

5. Um banco de dados foi criado para, em análise posterior, avaliar a correlação entre parâmetros de pluviometria e valores mensais e anuais do índice $\mathrm{EI}_{30}$, aqui calculados com registros pluviográficos, no sentido de simplificar o cálculo desse índice e agilitar a atual ização de seus val ores atéo ano 2000.

\section{LITERATURA CITADA}

ALBUQUERQUE, A.W.; LOMBARDI NETO, F.; CATANEO, A. \& SRINIVASAN, V.S. Parâmetros erosividade da chuva e da enxurrada correlacionados com as perdas de solo de um solo Bruno Não-Cálcico vértico em Sumé (PB). R. Bras. Ci. Solo, 22:743-749, 1998.

ALBUQUERQUE, A.W.; LOMBARDI NETO, F. \& SRINIVASAN, V.S. Efeito do desmatamento da caatinga sobre as perdas de solo e água de um Luvissolo em Sumé (PB). R. Bras. Ci. Solo, 25:121-128, 2001.

ALBUQUERQUE, A.W.; CHAVES, I.B. \& VASQUES FILHO, J. Características físicas da chuva correlacionadas com as perdas de solo num Regossolo eutrófico de Caruarú (PE). R.Bras. Ci. Solo, 18:279-283, 1994.

BERTOL, I. Índice de erosividade $\left(\mathrm{EI}_{30}\right)$ para Lajes (SC). $1^{\mathrm{a}}$. aproximação. Pesq. Agropec. Bras., 28:515-521, 1993.

BERTOL, I. Avaliação da erosividade da chuva na localidade de Campos Novos (SC) no período de 1981-1990. Pesq. Agropec. Bras., 29:1453-1458, 1994

BERTONI, J . \& LOMBARDI NETO, F. Conservação do solo. São Paulo, Í cone, 1990. 355p.

BROWN, L.R. The global loss of topsoil. J . Soil Water Conserv, 39:162-165, 1984.

CANTALICE, J.R.B. \& MARGOLIS, E. Características das chuvas e correlação de índices de erosividade com as perdas de solo do agreste de Pernambuco. R. Bras. Ci. Solo, 17:275281, 1993.

CARVALHO, M.P.; LOMBARDI NETO, F.; VASQUES FILHO, J . \& CATANEO, A. Erosividade da chuva de Mococa (SP) analisada peloíndiceEI ${ }_{30}$. R. Bras. Ci. Solo, 13:243-249, 1989.

CARVALHO, M.P. \& HERNANI, L.C. Parâmetros deerosividade da chuva e da enxurrada correlacionados com perdas de solo e erodibilidade de um Latossolo Roxo de Dourados (MS). R. Bras. Ci. Solo, 25:137-146, 2001.

CARVALHO, M.P.; PISSARA, T.C. \& PAULINO, H.B. Erosividade da chuva deSel víria (MS): distribuição, período de retorno e probabilidade de ocorrência. In: CONGRESSO BRASILEIRO DE CIÊNCIA DO SOLO, 26., Rio deJ aneiro, 1997. Anais. Campinas, Sociedade Brasileira de Ciência do Solo, 1997. CD-ROM 
CASTRO FILHO, C.; CAVIGLIONE, J.H. \& RUFINO, R.L. Determinação do potencial erosivo das chuvas da bacia do rio Paraná. $1^{a}$. aproximação. In: REUNIÃO BRASILEIRA DE MANEJ O E CONSERVAÇÃO DO SOLO E DA ÁGUA, 13., Ilhéus, 2000. Anais. Ilhéus, Sociedade Brasileira de Ciência do Solo, 2000. CD-ROM

CHAVES, I.B.; LEITE JÚNIOR, G.P. \& MAIA NETO, F.F. Análise da pluviometria e da erosividade das chuvas de Patos (PB). In: CONGRESSO BRASILEIRO DE CIÊNCIA DO SOLO, 26., Rio de J aneiro, 1997. Anais. Campinas, Sociedade Brasileira de Ciência do Solo, 1997. CD-ROM

COGO, N.P.; DREWS, C.R. \& GIANELLO, C. Índice de erosividade das chuvas dos municípios de Guaíba, Ijuí e Passo Fundo, no estado do Rio Grande do Sul. In: ENCONTRO NACIONAL DE PESQUISA SOBRE CONSERVAÇÃO DO SOLO, 2., Passo Fundo, 1978, Anais. Passo Fundo, CNPT/SNLCS-EMBRAPA, 1978. p. 145-152.

COLODRO, G.; CARVALHO, M.P.\& ROQUE, C.G. Erosividade da chuva: distribuição e correlação com a precipitação pluviométrica de Teodoro Sampaio (SP). In: REUNIÃO BRASILEIRA DE MANEJ O E CONSERVAÇÃO DO SOLO E DA ÁGUA, 13., Ilhéus, 2000. Anais. Ilhéus, Sociedade Brasileira de Ciência do Solo, 2000. CD-ROM

DEDECEK, R.A. Capacidade erosiva das chuvas de Brasília DF. In: ENCONTRO NACIONAL DE PESQUISA SOBRE CONSERVAÇÃO DO SOLO, 2., Passo Fundo, 1978. Anais. Passo Fundo, CNPT/SNLCS-EMBRAPA, 1978. p.157-161.

De MARIA, I.C. Erosão e terraços em plantio direto. B. Inf. SBCS, 24:17-21, 1999.

DIAS, A.S. A erosividade das chuvas em Fortaleza (CE): Distribuição, probabilidade de ocorrência, período de retorno e correlação com parâmetros pluviométricos. Fortaleza, Universidade Federal do Ceará. 2002. 42p. (Tese de Mestrado)

FOSTER， G.R.; MCCOOL，D.K.; RENARD， K.G. \& MOLDENHAUER, W.C. Conversion of the universal soil loss equation to SI metric units. J . Soil Water Conserv., 36:355-359, 1981.

HUDSON, N. Soil conservation. 3.ed. Ames, lowa State University Press, 1995. 391p.

LOMBARDI NETO, F. Rainfall erosivity - its distribution and relationship with soil loss at Campinas, Brazil. West Lafayette, PurdueUniversity, 1977. 53p. (Tesede Mestrado)

LOPES, P.C.R. \& BRITO, L.T.L. Erosividade da chuva no Médio São Francisco. R.Bras. Ci. Solo, 17:129-133, 1993.

MAGALHÃES, S.A.R. \& LIMA, R.R.A. Estratégia de desenvolvimento sustentável no Nordeste. In: MINISTÉRIO DO MEIO AMBIENTE, DOS RECURSOS HIIDRICOS E DA AMAZÔNIA LEGAL, ed. Desertificação em revista. Rio de J aneiro, 1995. 237p. CD-ROM

MAIA NETO, F.F. \& CHAVES, I.B. Mapeamento da erosividade das chuvas da Paraíba. In: CONGRESSO BRASILEIRO DE CIÊNCIA DO SOLO, 26., Rio deJ aneiro, 1997. Anais. Campinas, Sociedade Brasileira de Ciência do Solo, 1997. CD-ROM
MARGOLIS, E.; SILVA, A.B. \& J ACQUES, F.O. Determinação dos fatores da equação universal das perdas de solo para as condições de Caruaru (PE). R. Bras. Ci. Solo, 9:165-169, 1985.

MARQUES, J .J .G.S.M. Estimativas e comparações dos fatores erosividade das chuvas e erodibilidade de solos com horizonte B textural no Brasil. Lavras, Universidade Federal de Lavras, 1996. 119p. (Tese de Mestrado)

MARQUES, J.J.G.S.M.; ALVARENGA, R.C.; CURI, N.; SANTANA, D.P. \& SILVA, M.L.N. Índices de erosividade da chuva, perdas de solo e fator erodibilidade para dois solos da região dos cerrados - primeira aproximação. R. Bras. Ci. Solo, 21:427-434, 1997.

MINITAB. Minitab statistical software-Release 12. User's guide 1: data, graphics and macros. State College, 1998. Não paginado.

MORAIS, L.F.B.; MUTTI, L.S.M. \& ELTZ, F.L.F. Índices de erosividade correlacionados com perdas de solo no Rio Grande do Sul. R. Bras. Ci. Solo, 12:281-284, 1988.

MORAIS, L.F.B.; SILVA, V.; NASCHENVENG, T.M.C.; HARDOIN, P.C.; ALMEIDA, J.E.L.; WEBER, O.L.S.; $\mathrm{BOEL}, \mathrm{E}$. \& DURIGON, V. Índice $\mathrm{EI}_{30}$ e sua relação com o coeficiente de chuva do sudoeste de Mato Grosso. R. Bras. Ci. Solo, 15:339-344, 1991.

MOURA, A.R.B. \& MEDEIROS, J.F. Determinação inicial da erosividade da chuva (fator R) em 1985, em Mossoró (RN). R. Bras. Ci. Solo,11:229-231, 1987.

OLIVEIRA J r., R.C. \& MEDINA, B.F. A erosividade das chuvas em Manaus (AM). R. Bras. Ci. Solo, 14:235-239, 1990.

PISSARRA, T.C.T; CARVALHO, M.P. \& CHUEIRE, F.B. Erosividade da chuva de Pereira Barreto (SP): distribuição, período de retorno e probabilidade de ocorrência. In: REUNIÃO BRASILEIRA DE MANEJ O E CONSERVAÇÃO DO SOLO E DA ÁGUA, 13., Ilhéus, 2000. Anais. Ilhéus, Sociedade Brasileira de Ciência do Solo, 2000. CD-ROM

RENARD, K.G.; FOSTER, G.R; WEESIES, G.A. \& PORTER, J .P. RUSLE: Revised Universal Soil Loss Equation. J . Soil Water Conserv., 46:30-33, 1991.

RENARD, K.G.; FOSTER, G.R.; YODER, D.C. \& MCCOOL, D.K. RUSLE revisited: status, questions, answers and the future. J . Soil Water Conserv., 49:213-220, 1994.

ROQUE, C.G.; CARVALHO, M.P. \& PRADO, R.M. Fator erosividade da chuva de Piraju (SP): distribuição, probabilidade de ocorrência, período de retorno e correlação com o coeficiente de chuva. R. Bras. Ci. Solo, 25:147-156, 2001.

RUFINO, R.L.; BISCAIA, R.C.M. \& MERTEN, G.H. Determinação do potencial erosivo da chuva do Estado do Paraná através da pluviometria: terceira aproximação. R. Bras. Ci. Solo, 17:439-444, 1993.

SCHWAB, G.O.; FREVERT, R.K.; EDMINSTER, T.W. \& BARNES, K.K. Soil and water conservation engineering. 2.ed. New York, J ohn Wiley, 1966. 683p.

SILVA,J J.R.C.; SAUNDERS, L.C.U.; PAIVA, J .B. \& RODRIGUES, A.R. Erosividade das chuvas deQuixadá - Ceará: resultados do ano de 1980. Ci. Agron., 12:97-101, 1981. 
SILVA, J .R.C. A conservationist approach for Brazilian soils using a geographic information system. I thaca, Cornell University. 1990. 280p. (Tese de Doutorado)

SILVA, J .R.C. Erosão e produtividade do solo no semi-árido. In: OLIVEIRA, T.S.; ASSIS J R., R.N.; ROMERO, R.E.; SILVA, J .R.C., eds. Agricultura, sustentabilidade e o semi-árido. Viçosa, Sociedade Brasileira de Ciência do Solo/ Universidade Federal do Ceará, 2000. p.169-213.

SILVA, M.L.N.; FREITAS, P.L.; BLANCANEAUX, P. \& CURI, $N$. Índice de erosividade de chuva da região de Goiânia (GO). In: REUNIÃO BRASILEIRA DE MANEJ O E CONSERVAÇÃO DO SOLO E DA ÁGUA, 11., Águas de Lindóia. 1996. Anais. Águas de Lindóia, Sociedade Brasileira de Ciência do Solo, 1996. CD-ROM
SILVA, M.L.N.; CURI, N.; FERREIRA, M.M.; FONSECA, S. \& MARTINS, S.G. Erosividade das chuvas na região dos tabuleiros costeiros, município de Aracruz (ES) - Primeira aproximação. In: REUNIÃO BRASILEIRA DE MANEJ O E CONSERVAÇÃO DO SOLO E DA ÁGUA, 13., Ilhéus, 2000. Anais. I lhéus, Sociedade Brasileira de Ciência doSolo, 2000. CD-ROM

WISCHMEIER, W.H. Storms and soil conservation. J . Soil Water Conserv., 17:55-59, 1962.

WISCHMEIER, W.H. Use and misuse of the universal soil loss equation. J. Soil Water Conserv., 31:5-9, 1976.

WISCHMEIER, W.H. \& SMITH, D.D. Predicting rainfall erosion losses - A guide to conservation planning. Washington, USDA, 1978. 58p. 
